\title{
The Analysis of the Dilemma in Implementation of Green Finance in China
}

\author{
Tianyi Yang, ${ }^{1}$, Mohd Effandi Yusoff ${ }^{1}$ \\ ${ }^{1}$ Azman Hashim International Business School, Universiti Technologi Malaysia, Skudai, Johor Bahru, Malaysia
}

\begin{abstract}
With the overall transformation and upgrading of China's economic structure, the development concept of green finance has been established in the financial industry, but it is also facing new challenges in the near future. First, this article will summarize the previous studies of green finance. Based on the current finance development situation, this article will investigate the difficulties encountered in implementing green finance in China and finding solutions. The study aims to provide a theoretical reference for the development of green finance in China.
\end{abstract}

Keywords: Green Finance, Green Debt, Finance innovation.

\section{Introduction}

In recent years, environmental problems such as environmental pollution, resource depletion, and ecological imbalances that have emerged on a global scale have become increasingly urgent. Environmental issues have become global economic and political problems, which are related to human survival and social development. It has become a global consensus to strengthen ecological protection and achieve sustainable development. In the past 30 years, China's economy has maintained a relatively high growth rate, meanwhile, China becomes the world's second-largest economy. However, China's economic development mode is at the expense of the environment, making China's environmental problems more and more severe. The concept of green finance was first put forward in 1991 in order to alleviate environmental pollution and realize the sustainable development of mankind. Green finance is an effective means to promote the sustainable development of society, economy, and environment, but green finance is relatively slow due to its characteristics. In September 2015, in the "Overall Plan for Ecological Civilization System Reformation" issued by the Central Committee of the Communist Party of China and the State Council, China for the first time clarified the top-level design of China's green financial system. This article will summarize the relevant research on green finance in an international scale and study and analyze the difficulties encountered in the implementation of green finance in China and the solutions.

\subsection{Basic Concepts and Background of Green Finance}

\subsubsection{Basic Concepts}

Green finance, also was known as Environmental Finance and Sustainable Finance. Salazar suggested that green finance is a financial innovation that can build a path to environmental protection and a bridge between the financial industry and the environmental industry [1]. Cowan pointed out that green finance mainly discusses the development of the green economy and financing issues, and it is an interdisciplinary subject of green economy and finance [2]. Labatt and White stressed that green finance is a financial tool based on market research to improve environmental quality and reduce environmental risks [3]. Domestic scholars have also conducted extensive discussions on the connotation of green finance. Wang Junhua believes that green finance refers to the kind of financial activities that focus on the treatment of environmental pollution and the protection of the ecological environment during business activities [4]. The financial social funds will play a guidance role, and it will promote the coordination of economy and ecology and promote the coordinated development of economy and ecology. The goal of green finance is to achieve sustainable economic development. Based on this, Li Xinyin emphasized that green finance needs to pay attention to the environmental protection industry's development [5]. Although scholars have put forward different views on the concept of green finance, its core is still the concept of environmental protection and sustainable development. Therefore, green finance can be defined as solving environmental pollution and climate change through the optimal combination of financial tools and financial products to achieve sustainable economic, social and ecological development [6].

Green finance has explicitly the following forms: green credit, green insurance, and green securities. Green credit means that financial institutions (mainly banks) impose restrictions on loan lines for pollution production and new projects of polluting enterprises in order to promote enterprises to reduce pollution and charge punitive high interest rates; but for ecological protection and construction, research and development, production of pollution control facilities, environmental-friendly enterprises engaged in circular economy and green economic production financial institutions will provide relatively low interest rate loans. Green insurance is also known as environmental pollution liability insurance, and its subject matter is the liability for damages caused by a pollution accident. Green securities refer to the implementation of listed companies' environmental protection verification system and environmental information disclosure system, it can provide incentives and restraint mechanisms for listed companies. Green securities can limit the excessive expansion of "double high" (high energy consumption and high pollution) companies and promote listed companies' continuous environmental improvement. In addition, green finance can also cover green venture capital, green bonds, green funds, etc. [7]. 


\subsection{China's Green Finance Development}

In July 2007, the Ministry of Environmental Protection, the People's Bank of China, and the China Banking Regulatory Commission jointly issued the "Opinions on Implementing Environmental Protection Policies and Regulations to Prevent Credit Risks", which is the official establishment of China's green credit system. In February 2012, the China Banking Regulatory Commission issued the "Green Credit Guidelines", which set precise requirements for banking financial institutions to carry out green credit, promote energy conservation, emission reduction, and environmental protection. In September 2015, in the "Overall Plan for Ecological Civilization System Reform" issued by the Central Committee of the Communist Party of China and the State Council, China for the first time clarified the top-level design for establishing China's green financial system. In March 2016, the "Thirteenth Five-Year Plan" approved by the National People's Congress clearly stated that it is necessary to establish a green financial system, develop green credit, green bonds, and establish a green development fund. The establishment of a green financial system has risen to a country strategy in China. Since the "Guiding Opinions on Building a Green Financial System" issued by seven ministries and commissions in 2016 indicated that China's green finance had achieved tremendous breakthroughs. The innovation of the green financial system has been accelerated, and system construction has also been steadily advanced. The scale of trading Green credit, green bonds, green funds, and carbon in China ranks among the world's top. In 2019, the National Two Sessions emphasized the need to adhere to ecological priority and green development. According to a preliminary estimate by Political Zhengwei Lu [8], China's green finance investment and fiscal balance have approached 10 trillion yuan. Among green finance, green credit occupies a leading position, and its scale is growing stably. According to the "Video and Telephone Conference on Banking and Insurance Regulatory Work" held by the China Banking and Insurance Regulatory Commission on August 29, 2018, the balance of green credit loans exceeded 9 trillion yuan. However, while China's green finance is developing rapidly, many challenges affect sustainable development.

\section{The Necessity of Green Finance Development}

\subsection{Promote Sustainable Development}

Domestic scholars' research on green finance theory mainly starts from two perspectives of China's economic development model and the development of financial institutions themselves when expounding the importance and necessity of developing green finance. Yu Yongda and Guo Peiyuan pointed out that green finance can promote sustainable development [9]. In the long run, excessive consumption of resources and environmental pollution may lead to systemic risks, which will damage the operation and solvency of individual companies and severely damage the entire industry.

\subsection{Accelerate the Transformation of Industrial Structure}

The incentive and allocation effect of green finance can guide capital from heavy industries that rely on high energy consumption and high pollution to low energy consumption and environmentally friendly tertiary sectors. It is helpful to optimize the industrial structure of our country from extensive to intensive. Simultaneously, the inflow of funds will promote the development of environmental protection-related technologies, such as the development and application of clean energy, and most environmental protection-related industries are closely linked to high-tech. The development of related equipment manufacturing industries and services can also promote China's industrial structure. The transition from traditional low-value-added industries to high-value-added sectors.

\subsection{Reduce Financial Pressures Related to Environmental Protection}

The investment required for environmental pollution control is enormous, and the environmental recovery cycle is long and slow. If only relying on national and local finances, it will cause excessive pressure on the government's finances. For example, in five years, China's investment demand for pollution control is 1.7 trillion yuan, but the financial investment is estimated to be less than 100 billion yuan [10]. The considerable gap makes it challenging to achieve the goal of pollution control. It is impossible to curb the generation of pollution from the source effectively and temporarily remedy the environmental pollution that has been caused. With the establishment of an effective green financial system, limited fiscal funds (through discounted green loans, etc.) can leverage several to dozens of times of private funds to support green industries in a long-term and systematic manner fundamentally reduce environmental pollution.

\subsection{International Trends}

In December 2019, the European Commission's "European Green Agreement" mentioned that the European Union would regard the "Paris Agreement" as the core element of all future comprehensive trade agreements to promote trade and investment in green goods and services. All quasi-chemicals, materials, foods, and other products on the European market must meet the EU's relevant green regulatory requirements and standards, and "green" may become a new trade barrier. The European Union is one of China's largest export markets. After these green development-related trade policies are implemented, they will have a more significant impact on China. Therefore, China must follow international trends, accelerate green transformation, and enhance China's soft power and international trade voice.

\section{Difficulties in Implementation of Green Finance in China}

\subsection{Green Standards are Difficult to Define}

The economic impact caused by environmental damage is significant. The impact cycle is long, making it difficult to estimate the economic loss caused by environmental problems accurately, and the environmental protection costs are difficult to calculate. Therefore, the long-term benefits brought by green investment are difficult to measure, and the asset value of green financial products is difficult to evaluate. Simultaneously, the problem of information asymmetry is widespread, and it is difficult for financial institutions to determine whether a company is "green" or not. Profit and operating performance have always been the primary goals pursued by business operators. The application of environmental protection technology and investment in 
environmental protection equipment will increase business costs in the short term. This has led some companies to resort to "green wash" methods. Obtain financial support from green finance, but environmental factors and sustainable development are not considered in its daily business activities and investment decisions.

\subsection{Financial Institutions Lack Endogenous Motivation}

As the primary providers of green financial services, financial institutions have insufficient motivation to provide green financing. This is because green projects generally have the following characteristics: large-scale initial investment, low investment yield, long investment payback period, and severe maturity mismatch problems.Green projects focusing on energy conservation, emission reduction, pollution control, and other projects especially involve capacity investment or production equipment transformation and upgrading, construction and installation of treatment facilities and equipment, and operation and maintenance at the initial stage of the project completion. The initial investment scale is relatively large, and because green projects have positive environmental externalities, their yields are generally low, and the investment payback period is prolonged [11]. At the same time, environmental protection-related industries are emerging industries. Compared with traditional sectors, environmental protection-related industries have more significant uncertainty, and financial institutions have less investment experience, so less fundings. Besides, the general green finance financing objects are primarily small and medium-sized enterprises. Small and medium-sized enterprises are small in scale, weak in financial strength, unable to bear the burden of pollution control costs, coupled with limited management skills, lack of long-term investment planning, and inadequate awareness of sustainable development. Environmental problems for small businesses are generally more severe. However, such enterprises generally lack reliable and compelling collateral.

\subsection{Lack of Green Finance Professionals}

Green finance is a new and intersecting industry, integrating economy, finance, policy, environment, law, chemical industry, data analysis, and engineering, and has high practicality and skills. Due to the late start of domestic green finance, green finance talents are very scarce. At present, only the School of Finance of the Renmin University of China has established China's first master's degree in finance in the major of green finance[10]. The lack of an effective professional training mechanism will directly restrict the establishment of China's green financial system.

\section{Solutions and Conclusion}

Here are some suggestions for developing China's green finance: First, accelerate the establishment of a green financial standard system consistent with actual domestic conditions, is unified within the industry, is in line with international standards, and is quantified and executable. Second, introduce excellent international assessment models and localize them based on Chinese data to quantify enterprises' impact on the environment. The risk assessment of the production environment of a company is a vast and complex system. Therefore, green finance requires the coordination and cooperation of multiple departments such as financial supervision departments, enterprises, environmental protection departments, and financial institutions, such as mandatory environmental protection information and risk disclosure for listed companies. This requires the communication of information between financial regulatory agencies, listed companies, and environmental protection agencies. At the same time, with the help of Internet of Things technology, 5G technology, real-time pollution monitoring platform, big data analysis and other new technologies, a complete environmental monitoring and green information disclosure system can be established to provide financial institutions with a green database of the reference value. While improving the database, accelerate establishing a thirdparty professional evaluation platform, and adopt the model of colleges and universities + think tanks (research institutions) + financial institutions to provide technical service support for green finance.

It is very important to strengthen the supervision and restriction of non-green enterprises, and provide green enterprises with price subsidies, tax incentives and other policy incentives. Simultaneously, the government can make full use of green budget tools to redirect public investment, consumption, and taxation to green projects. In addition, it is also necessary to establish a compulsory green insurance system in high environmental risk industries. Most foreign green insurance is voluntary insurance by enterprises and shareholders to avoid possible future environmental legal risks. This is based on the relatively good environmental laws and regulations in foreign countries and vigorous law enforcement. According to the actual situation in China, it is possible to consider establishing a mandatory green insurance system in the form of legislation for industries with high environmental risks (such as smelting, heavy chemical industry, textiles, leather, etc.).

Reducing the risk weight of green assets can be the incentive for commercial banks to redistribute credit and capital to sustainable sectors of the economy. As early as implementing the first version of the Basel Agreement, the risk weight of real estate mortgage loans was set lower than that of ordinary loans, only 50\%. Subsequent empirical researchers almost all admitted that this regulation had caused a rapid and substantial increase in the proportion of real estate mortgage financing in bank assets [11]. Therefore, reducing the risk weight of green assets may become an effective means to guide bank assets' flow to green projects. From a short-term perspective, the risk of green projects has no special advantages over other projects; however, the accumulation of environmental risks may become a long-term systemic risk in the short term. If weather events occur frequently, normal economic activities may be significantly affected, which may increase banks' credit risk; the increase in environmental protection standards may cause a large number of companies in specific industries to be shut down. In the long run, because green projects consider and exclude environmental risks, they have a more significant advantage in avoiding such systemic risks with a considerable impact and are therefore safer and lower in credit risk than other projects with environmental hazards. In addition, Campiglio and Rozenberg also proposed introducing a differential reserve ratio to encourage green financing; at the same time, they also pointed out that the capital requirement may be more effective than liquidity in restricting bank lending. Therefore, by reducing the capital adequacy ratio requirement, it can be more effectively guided. Credit flows more to the green sector 
[12].

Accelerate the construction of localized green finance pilot projects, encourage institutions and schools to set up green finance talent training bases, and input successful experience and talent support to develop green projects in various regions. A single enterprise may have a large investment in environmental protection. Therefore, instructing enterprises to join incubators, industrial parks, etc. to form enterprise clusters can centrally optimize the solution of energy consumption requirements such as power supply and heating, and environmental protection requirements such as waste fertilizer and wastewater treatment, and even realize the reuse of industrial waste. This intensive environmental protection model can effectively reduce the environmental protection costs and financing needs of enterprises. At the same time, the green financing needs of SMEs can be transformed into the green financing needs of industrial parks, incubators, and enterprise clusters, which reduces the audit costs and risks of financial institutions.

Combining the supply chain to weaken the risk of green finance business. Although the risk of providing green financial services to a single SME is relatively high, each SME does not join the incubation base or industrial park in time and is also in a specific supply chain. As the core enterprises' upstream and downstream enterprises, SMEs provide supportive services for core enterprises' production and sales. Therefore, as long as the supply chain of SMEs and core enterprises is stable, financial institutions such as banks can include a single SME's integrity. The industrial supply chain is examined as a whole, and an evaluation and review system for the green financial supply chain is established. Banks and other financial institutions can provide small and medium-sized enterprises with green financial services, including financing support.

\section{References}

[1] Salazar, J. Environmental Finance: Linking Two World Financial Innovations for Biodiversity Bratislava(Bratislava, Slovakia, 1998). Vol. 1, p.2-18.
[2] Cowan, E. Topical Issues In Environmental Finance. Research Paper Was Commissioned by the Asia Branch of the Canadian International Development Agency (CIDA) ,1999. Vol. 1, p.120.

[3] Labatt, S. , White, R. Environmental Finance: A Guide to Environmental Risk Assessment and Financial Products (John Wiley \&Sons.Inc, Canada 2002.)

[4] Wang Junhua.On the "Green Revolution" of the Financial Industry. Ecological Economy, Vol. 10(2000), p.45-48.

[5] Li Xinyin.A humble opinion on the necessity and methods of green financial tool innovation. Journal of Liaoning Institute of Socialism, Vol. 4(2006), p.43-44.

[6] Deng Xiang.A Review of Green Finance Research.Journal of Zhongnan University of Economics and Law, Vol. 6(2012), p. 67-71.

[7] An Wei. A Preliminary Study on the Connotation, Mechanism and Practice of Green Finance. Economic Survey, Vol. 5(2008), p.156-158.

[8] Lu Zhengwei, Qian Lihua, Fang Qi. Challenges and countermeasures of developing green finance. Financial Electronics, Vol. 3(2019), p.10-12.

[9] Yu Yongda, Guo Peiyuan. Research and Practice of Financial Industry Promoting Sustainable Development. Environmental Protection, Vol. 12(2003), p.50-53.

[10] Ma Jun, Zhou Yueqiu, Yin Hong. China Financial Development and Case Studies(China Finance Press, China, 2017), p.133-142.

[11] Lu zhengwei, Fang qi. Financial Supervision and Green Finance Development: A Summary of Practice and Research.Financial Supervision Research, Vol.11, (2018), p.113.

[12] Emanuele Campiglio. Beyond carbon pricing: The role of banking and monetary policy in financing the transition to a low-carbon economy. Ecological Economics, Vol.1, (2016), p.121. 